\title{
A Scandinavian Approach to Designing with Children in a Developing Country - Exploring the Applicability of Participatory Methods
}

\author{
Nahid Wakil and Peter Dalsgaard \\ Participatory Information Technology Centre (PIT), Aarhus University \\ nahidwakil06@hotmail.com, dalsgaard@cavi.au.dk
}

\begin{abstract}
Participatory Design (PD) offers a democratic approach to design by creating a platform for active end-user participation in the design process. Since its emergence, the field of PD has been shaped by the Scandinavian context, in which many early PD projects took place. In this paper we discuss the challenges that arise from employing participatory methods in a different sociocultural setting with participants who have had comparatively limited exposure to digital technologies. We offer a comparative study of two PD projects carried out with school classes in Scandinavia and India. While the setup for the two projects was identical, they unfolded in very different ways. We present and discuss this study, which leads us to conclude that PD can be a useful approach in both settings, but that there is a distinct difference as to which methods bring about fruitful results. The most prominent difference is the ways in which $a b$ stract and manifest participatory methods led to different outcomes in the two settings.
\end{abstract}

Keywords: Participatory Design, Developing Countries, Interaction Design, Future Workshop, Inspiration Card Workshop, Mock-ups.

\section{Introduction}

In this paper, we address the Interact 2013 theme of 'Designing for Diversity' by examining how methods and techniques from Participatory Design (PD) translate from the setting in which they emerged, Scandinavia, to a rather different setting, namely an impoverished district in New Delhi, India. The aim of this work is to examine the role of PD and the challenges that arise from employing participatory methods in developing countries where access to and knowledge about technology and digital artifacts is yet relatively limited. As interaction designers increasingly work on projects outside of the settings in which participatory methods emerged and evolved, we find it pertinent to study if and how we can employ well known PD methods in new domains. Our work builds on the assumption that some methods may be employed more or less in their original format and setup, whereas other methods may need revision; some existing methods may prove of little or no use, while we may need to develop new methods to address issues at hand in new settings. Our work furthermore examines an assumption that we have encountered in various forums, 
namely that a relative lack of technological knowledge may limit the extent to which user can take part in shaping an interaction design process. In order to examine and challenge these assumptions, we have carried out a comparative study of two design projects with school children aged 12-19, one in India and one in Scandinavia. The setup and framing for the two projects was identical and consisted of employing three established PD methods: 1) a Future Workshop [Kensing \& Halskov 1991; Vidal 2006] 2) an Inspiration Card Workshop [Halskov \& Dalsgaard 2006] and 3) a Mockup session [Ehn \& Kyng 1991] to test, evaluate and develop the product. Since it is a single study, we focus on the specific findings; further studies are required to examine and develop more generalizable claims.

The contributions of this paper are two-fold. Firstly, we offer a comparative case study using the same methods within the same topic and frames in two design projects in very different domains, which in itself is rare in the field of HCI. Secondly, our analysis of the cases lead us to propose that the concept of abstract and manifest methods for user involvement can help practitioners select, frame and employ methods well-suited for the domain they work in.

\section{Background and Related Work: Beyond the Scandinavian Heritage of Participatory Design}

Participatory Design (PD) as a field is concerned with user involvement and decision making in the development of new technologies, in which "[...] the people destined to use the system play a critical role in designing it." [Schuler \& Namioka p. xi] Originating in Scandinavia in the 1980s, PD methods and approaches have since found widespread use, most notably in Europe and North America. The participatory agenda has also to some extent inspired systems and services thatrely upon participation in use [Dalsgaard, Dindler \& Eriksson 2008]. While methods and approaches inspired by PD have found an uptake outside of Scandinavia, there are few studies of how these methods translate to other settings. Recently, Zander, Georgsen \& Nyvang [2011] have examined the potential contributions of PD through a case study of a participatory development project in Bangladesh, pointing out the need to further explore the potentials of PD in this region. Banaji [2012] offers a harsh critique of current IT projects in the global south by stating that many of them are "painfully ignorant of the everyday realities" in these domains. Our work can be seen as a response to these concerns, in that we study the commonalities and differences in employing PD in design projects in Scandinavia and South Asia.

Examining the origins and development of PD, Gregory [2003] identifies three characteristics particular to Scandinavian PD: a deep commitment to democratisation, discussions of values in design and imagined futures, and the use of conflict and contraditions as resources for design. PD seeks to create a platform for active end-user participation in the design process, although there is not a fully formed consensus as to the scope and consequences of involving users. While some argue that users can serve as sources of inspiration for designers [Christiansen \& Kanstrup 2006], other contributions advocate a stronger role for users in design decisions. Kensing [1983] 
argues that there are three fundamental conditions of user participation in PD: access to relevant information, the possibility for taking an independent position on the problems and participation in decision making [Kensing, F., 1983]. These conditions emphasize an active engagement with end users, which have informed our studies in this paper. Muller [2002] argues that successful PD methods bring about a 'third space', a shared conceptual space in between designers' and users' respective domains, in which potential futures can be explored, developed and examined in collaboration. In the work presented here, we have built on these insights to establish what we label direct user involvement, based on the criteria that users should be involved in early stages of a project and take part in defining problems and visions as well as ongoing design decisions.

\section{Case Study: Participatory Workshops in India and Scandinavia}

In order to examine the applicability of participatory methods, we carried out two design projects with identical setups and framing. The first project took place in New Delhi, India, while the second project took place in Aarhus, Denmark. Here we present the setup of the design projects and the findings from India and Scandinavia, respectively.

\subsection{Setting Up the Design Projects}

We set up agreements with two schools to carry out a week-long design project with primary school pupils aged $12-19^{1}$. Each project was introduced and framed in the same way in order for us to examine the differentiation in use of participatory methods in a developing country and a Scandinavian country. The workshops were held in the children's classrooms in their respective schools and the theme for the workshops in both India and Scandinavia was how technology can be used to improve everyday life? We employed three established participatory methods to involve the users from the very beginning of the design project: Future Workshop [1] to define problems in the current situation, Inspiration Card Workshop [2] which was employed to develop ideas on how problems can be solved using inspiration materials and mock-up sessions [3] to test, evaluate and develop the product. In order to maintain the children's attention in the workshops, they were introduced to one phase at a time. And to maintain equal frames in both domains the teachers were present during all events. The children worked in groups and every group was asked to choose a spokesperson for the presentations after each stage. All events were documented in recordings and extensive field notes which were subsequently codified, condensated and analyzed.

\footnotetext{
${ }^{1}$ In the Scandinavian case, the school groups pupils in classes based on age, whereas the Indian school groups pupils on the basis of competencies, hence the spread in age.
} 


\subsection{Findings from the Workshops in India}

Starting with the critique phase in the Future Workshop the children were asked to brainstorm over the problems they meet in their everyday lives. As the children only wrote down a few words within the given time, an ongoing adjustment of the estimated time became necessary. They were confused and uncomfortable with the situation. The children then were asked to write down at least five problems in the next five minutes. The time pressure made them work effectively but at the same time they needed to be confirmed that what they wrote down were "real" problems.

In the following fantasy phase each group were asked to choose 2-3 problems to discuss and solve using technology. In the presentations the children mentioned the opposites of the problems as solutions; e.g. the problem "mathematics" was solved by not having the subject at all. And the problem "being pushed in the bus" was solved by "not having many people in the buses". The setup did not lead them to use their imagination to solve the problems, resulting in breakdowns in the ideation process. However, due to limited time we decided to move on to the next phase. In the Inspiration Card Workshop the children were introduced to the inspirational material in the form of inspiration cards and digital products such as cell phones, disc-players, iPods, calculators, CDs etc. The inspiration cards ended up in a row and were not moved any further. None of the groups combined the cards or developed their own cards. The blank cards, however, were used to write the definitive "answer" on. No new concept or idea was presented and the workshop resulted in seven already existing concepts directly copied from the inspirational material; the "mathematics" problem was solved by using a calculator and the "feeling alone" problem was solved by "talking on the phone with friends" etc.

Since some of the groups had expressed a desire for a cleaner city, we chose to work with the concept "Cleaning machine". The final concept was a trash can with a coin system, inspired by deposit systems. We developed a basic mock-up, which was first tested through plays and then evaluated and developed in a second workshop. To simulate an outdoor environment garbage was thrown on the classroom floor. The scene was presented to the children but the coin function was not mentioned, as we wanted to avoid predetermining the test. The children could buy chips and rice cakes on paper plates with paper coins in the shop. The trash can was located close to the shop and the teacher had written "trash" on the trash can in Hindi. Two children acted as salesmen and one boy was responsible for the trash can coin system. The rest of the class lined up in front of the shop and none of them noticed the garbage on the floor. Once the coin system was discovered all of the children wanted to get rid of their paper plates.

After the mock-up test the groups discussed what they liked and disliked about the trash can and how they could improve it. Although the groups still had the same spokesperson it was not easy for them to present their ideas. They were careful about saying anything "wrong" or "negative" about the trash can. Instead we asked them to draw a trash can using their imagination. Surprisingly, this gave very good results indeed. The children were creative and imaginative and used technology as a part of the solution. They improved the functionality, suggested a better way to interact with the trash can, mentioned the social aspect of how to get people wanting to use the trash can, suggested a better visual appearance, mentioned health problems that garbage can cause and how it could be solved and not least they considered the eco system to create 
power for robotic trash cans. Their independent input showed an understanding of the concept the mock-up has presented through a variety of creative ideas.

\subsection{Findings from the Workshops in Scandinavia}

In the critique phase the Danish children easily wrote down many things that they would like to change. This phase proceeded as expected and due to limited time the children presented only selected problems. In the fantasy phase the groups chose 2-3 problems to discuss and solve using their imagination and technology. The presented ideas were creative and imaginative and in the presentations the group discussed the presented concepts and ideas by asking each other question.

In the Inspiration Card Workshop the inspiration cards were used actively and the children also made their own cards. Few were inspired by the digital products and used sound as a part of the solution. In the presentations the groups defended their own ideas as the best. They had concrete scenarios in mind and were precise about the concept details. They were very specific in the choice of technology and it was obvious that they drew on their own experiences in the development of new concepts. The workshop resulted in five new creative concepts and the final product was a "memory box" based on the children's wish of an easier teenage life. The memory box had a scanning system to help the teenager remember things by placing her bag or wallet inside the box.

In the second workshop, the mock-up session, the memory box was tested, evaluated and to a certain limit improved. Three children were controlling the memory box by switching out the screens, changing the buttons to the right color and controlling the sound, which was played on an iPhone. One played the role of a busy teenager using the memory box while the rest of the class watched the play. After the mock-up test the groups were asked to answer a number of questions about how the memory box could be improved. Although the groups made a number of suggestions, the new memory boxes resembled the mock-up and had roughly the same functions and features. Many of the groups were locked into the idea of a square box with its already existing functions. One group made an egg shaped box and another came up with the idea of a camera function while the rest of the improvements referred to the box color.

\section{Discussion}

While both design projects led to interesting results and can be considered successful in bringing about new concepts through direct user participation, the ways in which the pupils arrived at them differed substantially. In the following, we compare the projects and introduce the notion of abstract and manifest design methods in order to account for these differences and discuss the applicability of participatory methods across different socio-cultural settings.

\subsection{Comparing the Design Projects in India and Scandinavia}

The first stages of the design process in India were problematic. The pupils were reluctant to engage in the design activities and were cautious in discussing events. They had trouble articulating problems and design opportunities, leading to breakdowns. 
This required ongoing adjustments and interventions from the facilitator in order to keep the process going. The two workshops were characterized by limited creative output and independent proposals. However, the mock-up session really turned things around, spurring creativity and out of the box thinking that also led them to revisit aspects that had been troubling in earlier stages. It was only in this stage that a true 'third space' was established. In the Scandinavian design project, things unfolded in almost the exact opposite way. The pupils were initially open towards the project and eager to discuss both the general project and the specific events. In both workshops, they also worked effectively and imaginatively and put forward new ideas and proposals. In many ways, these workshops unfolded, as we would expect on the basis of previous experience and accounts in literature. However, the relative level of creative output waned in the mock-up session. The ideas put forward resembled the existing one, and the proposals for changes were superficial. Table 1 summarizes the projects.

Table 1. Summary of the design projects in India and Scandinavia

\begin{tabular}{|l|l|l|}
\cline { 2 - 3 } \multicolumn{1}{c|}{} & India & Scandinavia \\
\hline General attitude & $\begin{array}{l}\text { Reluctant, cautious } \\
\text { No discussions }\end{array}$ & $\begin{array}{l}\text { Open, relaxed } \\
\text { Eager to discuss }\end{array}$ \\
\hline Future Workshop & $\begin{array}{l}\text { Three breakdowns } \\
\text { More time required }\end{array}$ & $\begin{array}{l}\text { No breakdowns } \\
\text { Work effectively on the tasks }\end{array}$ \\
\hline $\begin{array}{l}\text { Inspiration Card } \\
\text { Workshop }\end{array}$ & $\begin{array}{l}\text { Limited creativity } \\
\text { Limited independent proposals }\end{array}$ & $\begin{array}{l}\text { Good ideas } \\
\text { Creative, imaginative }\end{array}$ \\
\hline Mock-up & $\begin{array}{l}\text { Creative, imaginative } \\
\text { Active out of the box thinking }\end{array}$ & $\begin{array}{l}\text { Design fixation } \\
\text { Limited creative proposals }\end{array}$ \\
\hline
\end{tabular}

Comparing the two projects, the loose and open structure of the first two workshops seemed to limit the engagement of the Indian pupils, whereas it was well received by the Scandinavian pupils. If we reconsider the aforementioned criteria for PD, it proved difficult to establish a productive session in spite of providing access to relevant information and allowing for the pupils to take an independent position on the problems and participation in decision making [Kensing 1993]. The Indian pupils conceived of the facilitator as an authoritative figure possessing the 'right answers' in the design project up until the mock-up session. The Scandinavian pupils, on the other hand, had no problems taking on the roles of position as co-creators in the initial phases, however they experienced design fixation when exposed to the mock-up.

\subsection{Abstract and Manifest Methods for User Participation}

The contrast in how the two design projects in terms of active participation and creative output is quite striking. In light of our objective of understanding if and how traditional PD methods can be employed in different domains, we have analyzed setup of the three PD methods in more detail. If we first consider the Future Workshop, it can be construed as being relatively abstract, in that it offers a loose framing in which the pupils' point of departure was their own situation and preconceptions. The Inspiration 
Card Workshop is also relatively abstract but with certain manifest properties, in that while it offers tangible representations of technologies and domain concerns but does not prescribe how they are to be combined; this relies on the pupils' preconceptions. Finally, the mock-up sessions can be defined as manifest, in that they offer a concrete artifact that brings the potential technology to life in a tangible form. In the two projects, we thus find a clear correlation between the abstract and manifest properties of the methods and the perceived creative output from the pupils (see Figure 1).

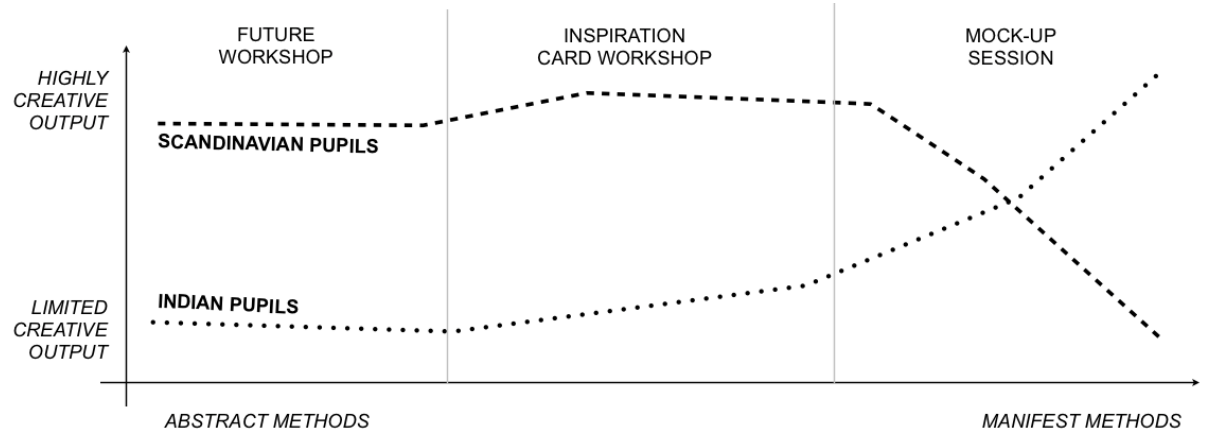

Fig. 1. Correlation between creative output and abstract/manifest properties of the PD methods

If we seek to understand why this correlation occurs, at least two prominent factors come into play: a) the Scandinavian pupils were accustomed to project-based group work, whereas the framing of school work for the Indian pupils was more traditional and rule-bound; b) the Scandinavian pupils were very familiar with interactive technologies and used them throughout their day, whereas the Indian pupils had relatively limited knowledge of them. Taken together, this indicates that if a design project is oriented towards technological solutions and the technological knowledge among participants is limited, the abstract representations offered in the traditional setup of the Future Workshops and Inspiration Card Workshops, which typically work well in Scandinavian settings, may not be sufficient to facilitate active participation. This is compounded if participants are not accustomed to the open and project-oriented format of the methods. On the other hand, the mock-up session as a manifest method was more productive by offering hands-on experiences and prompting participants to explore potential futures through construction.

\section{Conclusions and Future Work: Applicability of Participatory Methods across Different Socio-cultural Settings}

Our findings from the comparative case studies lead us to argue that PD can indeed be a useful approach in a domain that differs substantially from the Scandinavian setting in which the field emerged. However, it is also clear from our findings that existing methods cannot be expected to yield the same outcomes across domains, to the extent that some methods may not be advisable for use in their current form. While a 
multitude of factors affect the outcome of a design project - many of which are beyond the scope of a short paper to address or even introduce - we suggest that the concept of abstract and manifest methods can enrich our understanding of the outcomes of user participation. Abstract methods rely on preconceptions and imagination and limited use of materials. Manifest methods involve the use of materials and artifacts as the basis for inspiration and creativity. We speculate that many of existing methods that rely on abstract components may need to be revised if they are to be useful in radically new domains. Encouraged by the success of the mock-up session in the New Delhi case, we suggest that manifest methods may be a good starting point for participatory projects or events, and that researchers and practitioners consider developing new methods for user participation with manifest properties.

Concerning the validity and generalizability of the findings, our work relies on one comparative case study, and we most definitely need more studies and reports from PD practitioners in order to challenge, corroborate and expand upon these findings. We hope to explore these issues in future studies and invite our colleagues in the Interact community to take part.

\section{References}

1. Banaji, S.: Beyond Wild Dreams and High-Tech Fetishes: Learning about Media from Children in the Global South. Keynote Address, IDC 2012 (2012)

2. Christiansen, E., Kanstrup, A.M.: Selecting and evoking innovators: combining democracy and creativity. In: Proc. NordiCHI 2006, Oslo, Norway, pp. 321-330 (2006)

3. Dalsgaard, P., Dindler, C., Eriksson, E.: Designing for participation in public knowledge institutions. In: Proc. NordiCHI 2008, Lund, Sweden, pp. 93-102 (2008)

4. Ehn, P., Kyng, M.: Cardboard Computers: Mocking-It-Up or Hands-On the Future. In: Kyng, M., Greenbaum, J. (eds.) Design at Work: Cooperative Design of Computer Systems, pp. 169-196. Lawrence Erlbaum (1991)

5. Gregory, J.: Scandinavian Approaches to Participatory Design. International Journal of Engineering Education 19(1), 62-74 (2003)

6. Halskov, K., Dalsgaard, P.: Inspiration Card Workshops. In: Proc. DIS 2006, pp. 2-11 (2006)

7. Kensing, F.: The Trade Unions Influence on Technological Change. In: Briefs, U., et al. (eds.) Systems Design For, With and By the Users. North Holland (1983)

8. Kensing, F., Halskov, K.: Generating Visions: Future Workshops and Metaphorical Design. In: Kyng, M., Greenbaum, J. (eds.) Design at Work: Cooperative Design of Computer Systems, pp. 155-167. Lawrence Erlbaum (1991)

9. Schuler, D., Namioka, A. (eds.): Participatory design: Principles and practices. Lawrence Erlbaum, Hillsdale (1993)

10. Vidal, R.V.V.: The Future Workshop, Creative and Participative Problem Solving, pp. 1-21 (2006)

11. Zander, P.-O., Georgsen, M., Nyvang, T.: Scandinavian Participatory Design - Beyond Design, Beyond Scandinavia. In: Proc. of The Future of Development Research (2011) 